\title{
The Mobilization of Splenic Reservoir Myeloid- Derived Suppressor Cells in Sepsis-Induced Myocardial Injury
}

Cong Fu ( $\sim$ fucong7706@163.com )

Yi Ji Shan hospital https://orcid.org/0000-0002-4306-0594

Qiancheng Xu

Yi Ji Shan hospital

Shengxing Tang

Yi Ji Shan hospital

Yuhan Cao

Yi Ji Shan hospital

Can Liu

Yi Ji Shan hospital

Juan Li

Second peoples' hospital of Wuhu

Yihua Wang

Yi Ji Shan hospital

Yan Qian

Second peoples' hospital of Wuhu

Fei Shi

Wuhu hospital for traditional chinese medicine

Jingmin Gui

No 1 peoples' hospital of Wuhu

Qun Fan

Yi Ji Shan hospital

Yang Ling

Yi Ji Shan hospital

Research article

Keywords: Sepsis, Myocardial injury, MDSCs; Inflammation, mTOR

Posted Date: February 21st, 2019

DOI: https://doi.org/10.21203/rs.2.363/v1 
License: (c) (i) This work is licensed under a Creative Commons Attribution 4.0 International License. Read Full License 


\section{Abstract}

Background Myeloid-derived suppressor cells (MDSCs) play key roles in sepsis, but whether bone marrow is considered the only source remains unclear. The current knowledge about the mechanism of MDSCs leading to myocardial injury in sepsis is poor. Methods In sepsis patients with cardiac dysfunction, the circulating percentage of CD14-CD11 b+ and serum concentrations of IL- 6 and IL-1 $\beta$ were measured. A mouse sepsis model was established through caecum ligation and puncture (CLP). Animals were divided into four groups: control, sham, CLP and CLP+splenectomy (CLPS). Plasma concentrations of IL-6, IL-1 Tnl and NT-proBNP were measured. CD11 $+\mathrm{Gr}-1+$ cells were detected by immunofluorescence staining and RT-PCR. Myocardial injury was detected by HE, Masson and TUNEL staining. The expression of mTOR, P53 and caspase-3 was measured by Western blot. Results In sepsis patients, circulating MDSCs were increased, and the plasma concentrations of IL- 6 and IL-1 $\beta$ were elevated. The plasma concentrations of IL- 6 and IL-1 $\beta$ were correlated with the ratio of circulating MDSCs. In the mouse sepsis model, the spleen was the major source of $C D 11 b+G r-1+$ cells that migrated into circulation and the heart in sepsis. The serum concentrations of IL- 6 and IL-1 $\beta$ were also elevated. Echocardiography and serum biomarkers showed that cardiomyocyte damage and cardiac hypofunction in sepsis induced myocardial imjury. The expression of CD11b, Gr-1 and pro-inflammatory cytokines in the heart was significantly higher in sepsis patients than that in controls. Pathological staining and TUNEL staining showed obvious myocardial damage and cell apoptosis. The Western blot analysis indicated that in the heart, the activation of mTOR was inhibited and that the expression of P53 and caspase- 3 was elevated in sepsisinduced myocardial injury. Conclusion In sepsis-induced myocardial injury, splenic reservoir CD11b+Gr-1+ cells rapidly migrated into circulation and the heart, further impairing heart function via the high expression of P53 through the inhibition of mTOR.

\section{Background}

Sepsis is a severe and complicated syndrome that has high mortality. Myocardial injury is a common complication of sepsis in clinical practice. A growing amount of evidence suggests that myeloid cells are a major component in the role of promoting inflammation [1-3]. Recent studies have suggested that myeloid-derived suppressor cells (MDSCs) include immature granulocytes, macrophages and dendritic cells at different stages of differentiation [4]. Both in sepsis and trauma, MDSCs participate in the progression of inflammation $[5,6]$. In sepsis, the activation of MDSCs is related to pro-inflammatory cytokine production. Furthermore, MDSCs can regulate T cell responses through the production of large amounts of nitric oxide (NO) and reactive oxygen species (ROS) [7, 8]. However, the role of MDSCs needs to be further discussed.

The major known functions of the spleen are the removal of ageing erythrocytes and recycling of iron, elicitation of immunity, and supply of erythrocytes after haemorrhagic shock [9]. The presence of numerous monocytes in the spleen contribute to the progress of inflammation. A previous study showed that the spleen has numerous MDSCs that express $\mathrm{Gr}-1+\mathrm{CD} 11 \mathrm{~b}+$. In a mouse myocardial infarction model, the increased circulating MDSCs did not originate in the bone marrow. However, a great number of 
splenic MDSCs were recruited into the blood [10]. Although it has been suggested by other research that in an animal sepsis model, CD11b+Gr-1+ MDSCs gradually increase [6], the behaviour and origin of the MDSCs remains unclear in sepsis-induced myocardial injury.

Accordingly, this study was designed to confirm whether the number of circulating MDSCs increase and are further recruited into the myocardial tissue, leading to sepsis-induced myocardial injury. Further, we aimed to determine the origin of circulating MDSCs. Moreover, the preliminary mechanism of MDSC recruitment and myocardial injury was discussed.

\section{Methods}

\section{Sepsis patients}

Peripheral venous blood samples were collected from patients with sepsis and cardiac injury/dysfunction $(n=10)$ in the Emergency Department Intensive Care Unit of Yi Ji Shan Hospital affiliated with Wan Nan Medical College ( $n=2)$, Department of Critical Care Medicine of Wuhu No. 1 Peoples' Hospital $(n=2)$, Department of Critical Care Medicine of Wuhu No. 2 Peoples' Hospital $(n=5)$ and Department of Critical Care Medicine of Wuhu Traditional Chinese Medicine Hospital $(n=1)$. Human blood samples were collected in accordance with the medical ethics committees of Yi Ji Shan Hospital, Wuhu No. 1 Peoples' Hospital, Wuhu No. 2 Peoples' Hospital and Wuhu Traditional Chinese Medicine Hospital and performed according to the Declaration of Helsinki. This study was approved by Yi Ji Shan Hospital Ethics Committee and have informed consent from all patients and healthy control. Samples from 6 age- and sex-matched healthy volunteers were collected as controls. Peripheral venous blood samples were collected into EDTA-coated tubes and a procoagulant tube. Plasma was then separated from the procoagulant tube, collected into EP tubes and stored at $-40^{\circ} \mathrm{C}$. Plasma concentrations of IL- 6 and IL- $1 \beta$ were measured using a Human IL-6 ELISA kit and a Human IL-1 $\beta$ ELISA Kit (Boster, China), respectively. Mononuclear cells were isolated on hydroxypropyl methylcellulose (HaoYang, China) by centrifugation at $500 \mathrm{~g}$ for $20 \mathrm{~min}$. Cells were fixed in 1\% BSA in PBS. The cells were then incubated with PE-conjugated anti-Human CD14 (BD Biosciences, USA) and FITC-conjugated anti-Human CD11b (BD Biosciences, USA) for $1 \mathrm{~h}$ on ice. After washing three times with 1\% BSA in PBS, cells were analysed on a FACScan flow cytometer (Becton Dickinson, USA) to detect CD14-/CD11b+ cells.

\section{Animal sepsis model}

A sepsis model was generated in male C57BL/6J mice (8-10 weeks old, weight: $20-25 \mathrm{~g}$ ) via caecum ligation and puncture (CLP). The C57BL/6J mice were purchased from Qing Long Shan Animal Breeding Farm, Nanjing, China. All the mice were fed in SPF animal House. This animal study was approved by the Yi Ji Shan Hospital Animal Care Committee. The mice were handled according to the guidelines of the Local Ethics Committee for Animal Experimentation. Written informed consent to use the animals was obtained from Yi Ji Shan Hospital Animal Care Committee. The mice were randomly divided into four groups: control non-operated (control, $n=5)$, control operated (sham, $n=5), \operatorname{CLP}(n=10)$ and CLP+splenectomy (CLPS, $n=10$ ). Sepsis was induced by CLP based on previous descriptions $[11,12]$. 
Briefly, mice were anaesthetized intraperitoneally with $1 \%$ pentobarbital (Sigma, $35 \mathrm{mg} / \mathrm{kg}$ ). The caecum was ligated with a 5.0 silk suture at its base and then punctured one single time with a 26-gauge needle. After the caecum was placed back in the abdominal cavity, the peritoneal wall and skin incision were sutured. Sham group mice underwent a similar surgery without ligated or punctured. CLPS mice underwent the same procedure of CLP after splenectomy. All mice received $1 \mathrm{ml}$ of sterile saline subcutaneously after surgery. No antibiotics or anti-inflammatories were administered. After $24 \mathrm{~h}$ of the sepsis model, all mice were sacrificed under deep anaesthesia with overdose pentobarbital (Sigma, 130 $\mathrm{mg} / \mathrm{kg}$ intraperitoneal injection).

\section{Echocardiography}

After $24 \mathrm{~h}$ of the sepsis model established, 2-dimensional echocardiography was performed on the mice using a transthoracic echocardiogram (Visual Sonic, Canada) as previously described [13]. The ejection fraction (EF) was measured and the shortening fraction (FS) was calculated.

\section{Determination of plasma concentrations of IL-6, IL-1 $\beta, \mathrm{TnI}$ and NT-proBNP in animal model}

After echocardiography was performed, mice were sacrificed. Mouse blood was collected into an EDTAcoated tube. After centrifugation at $500 \mathrm{~g}$ for $20 \mathrm{~min}$, plasma was collected. Plasma concentrations of IL6, IL-1 $\beta$, Tnl and NT-proBNP were analysed using a Mouse IL-6 ELISA Kit (Beyotime, China), Mouse IL-1 $\beta$ ELISA Kit (Beyotime, China), Mouse TnI ELISA Kit (Enzyme-linked Biotechnology, China) and Mouse NTproBNP ELISA Kit (Elabscience, China), respectively.

\section{Cells preparation for FACS analysis}

Bone marrow-derived cells (BMDCs) from the femurs of euthanized mice were flushed with ice-cold PBS containing 1\% BSA and depleted of red blood cells (RBCs) using RBC lysing buffer (BD Biosciences). The spleen was cut into small pieces, grinded into cell suspension and depleted of red blood cells (RBCs) using RBC lysing buffer (BD Biosciences) (except for CLPS). Total nucleated cells in the peripheral blood were isolated after erythrocyte lysis. For the FACS analysis, cell suspensions were stained with PEconjugated anti-mouse CD11b antibodies and FITC-conjugated anti-mouse Gr-1 for $1 \mathrm{~h}$ on ice, and then they were washed with $1 \%$ BSA in PBS. The percentage of $\mathrm{CD} 11 \mathrm{~b}+/ \mathrm{Gr}-1+$ cells was evaluated by multicolour flow cytometry using a flow cytometer (EPICS ${ }^{\circledR}$ ALTRA, Beckman Coulter).

\section{mRNA expression of CD11b, Gr-1, IL-6 and IL-1 $\beta$ in myocardium of mice}

In mouse hearts, mRNA levels of various factors, including CD11b, Gr-1, IL- 6 and IL-1 $\beta$, were detected by RT-PCR. The mouse hearts were stored in Trizol at $-80^{\circ} \mathrm{C}$. Total RNA was extracted as previously described and cDNA was synthesized using a PrimeScriptTM RT reagent kit with gDNA Eraser (TAKARA, Japan). RTPCR was performed using CD11b primers (Forward: CCATGACCTTCCAAGAGAATGC, Reverse: ACCGGCTTGTGCTGTAGTC), Gr-1 primers (Forward: TCATCCTTCTTGTGGTCCTA, Reverse: AAGGGGCAGGTAGTTGTG), IL-6 (Forward: TAGTCCTTCCTACCCCAATTTCC, Reverse: TTGGTCCTTAGCCACTCCTTC), IL-1 $\beta$ (Forward: GCAACTGTTCCTGAACTCAACT, Reverse: 
ATCTTTTGGGGTCCGTCAACT) and GAPDH (Forward: GCCTCAAGATCATCAGCAAT, Reverse: GGACTGTGGTCATGAGTCCT). After RT (50 $\mathrm{C}, 30 \mathrm{~min})$, hot start (94 $\left.{ }^{\circ} \mathrm{C}, 15 \mathrm{~min}\right)$, and 40-42 cycles of PCR $\left(94^{\circ} \mathrm{C}, 1 \mathrm{~min} ; 52.5^{\circ} \mathrm{C}, 1 \mathrm{~min} ; 72^{\circ} \mathrm{C}, 1 \mathrm{~min}\right), \mathrm{CD} 11 \mathrm{~b}, \mathrm{Gr}-1, \mathrm{IL}-6$ and IL-1 $\beta$ mRNA expression was normalized to GAPDH and calculated as $2-\triangle \triangle \mathrm{Ct}$.

\section{Cardiac histopathology}

The myocardial tissue was fixed in 10\% formaldehyde, and then embedded in paraffin. Tissue sections (2 $\mu \mathrm{m}$ thick) were stained with haematoxylin and eosin (HE) and Masson staining using an HE Staining Kit (Beyotime, China) and Masson Staining Kit (NanJing KeyGen Biotech, China), respectively, according to the manufacturer's protocol. Morphological changes of myocardial tissue were assessed using an optical microscope (Olympus, Tokyo, Japan). The morphological evaluations were performed in a blinded manner by 2 independent investigators.

\section{Immunofluorescence staining}

A frozen section of heart was prepared. The myocardial tissue section ( $2 \mu \mathrm{m}$ thick) was stained with PEconjugated anti-mouse CD11b antibodies and FITC-conjugated anti-mouse Gr-1 for $1 \mathrm{~h}$ at room temperature to measure the expression of CD11b and Gr-1. The tissue was further stained with 4,6diamidino-2-phenylindole (DAPI, Roche). Fluorescence microscopy (Olympus, Tokyo, Japan) was used to detect the fluorescence.

\section{TUNEL immunohistochemistry (IHC) staining}

Terminal deoxynucleotidyl transferase-mediated dUTP nick end labelling (TUNEL) was performed to detect apoptotic nuclei by TUNEL Staining Kit (Roche, Indianapolis, IN) according to the manufacturer's protocol. The number of apoptotic cells with TUNEL-positive nuclei was counted by 2 independent observers blinded to the treatment group and expressed as a percentage of the total myocyte population.

\section{Western blot analysis}

For the Western blot analysis, protein was extracted from mouse myocardial tissue using a Tissue Protein Extraction Kit (Beyotime, China) according to the protocol provided by manufacturer. Protein concentrations were measured using the BCA Assay Kit (Pierce, USA). Western blots of the protein samples were performed to detect the mammalian target of rapamycin (mTOR) and phosphorylated Ser2448-mTOR (P-Ser2448 mTOR) using rabbit monoclonal anti-mouse mTOR antibodies and the rabbit monoclonal anti-mouse phosphorylated Ser2448-mTOR antibody (Cell Signaling Technology, USA). P53 and caspase-3 expression were detected by rabbit monoclonal anti-mouse P53 (Cell Signaling Technology, USA) and rabbit anti-mouse caspase-3 (Abcam, UK). GAPDH was used as a loading control (KangCheng Bio-tech, China). After primary antibody incubation, the blots were incubated with the appropriate secondary horseradish peroxidase conjugate mouse monoclonal anti-rabbit antibody (Boster, China). Each membrane was washed and then developed using Super Signal chemiluminescent substrate (Pierce, USA). 


\section{Statistical analyses}

For all experiments, the data were analyzed using either a Student's t-test or Bonferroni's test, and values are expressed as the means \pm SEM. All statistical analyses were performed using SPSS software (SAS Institute Inc., USA); $p$ values $<0.05$ were considered to indicate significance.

\section{Results}

Increased CD14-CD11b+ cells and plasma concentration of inflammatory factors in peripheral circulation of sepsis patients with myocardial injury

No differences in age or sex were found between the sepsis with myocardial injury group $(n=10)$ and the control group $(n=6)$. The percentage of CD14-CD11b+MDSCs was higher in the sepsis group than in the control group ( $88.1 \pm 5.3 \%$ vs $53.4 \pm 9.1 \%, P<0.05$, figure 1 ). Furthermore, the plasma concentrations of IL- 6 and IL-1 $\beta$ in sepsis patients were significantly higher than in controls $(24.0 \pm 1.4 \mathrm{pg} / \mathrm{mL}$ vs $16.7 \pm 1.0$ $\mathrm{pg} / \mathrm{mL}$ and $11.4 \pm 1.4 \mathrm{pg} / \mathrm{mL}$ vs $7.4 \pm 0.5 \mathrm{pg} / \mathrm{mL}$, respectively, $P<0.05$, figure $2 A, B)$. Furthermore, the plasma concentrations of IL- $6(r=0.728, P<0.001)$ and IL-1 $\beta(r=0.884, P<0.001)$ were statistically related to the percentage of CD14-/CD11b+ cells in the blood (figure 2C, D).

The percentage of CD11b+Gr-1+ cells in blood, spleen and bone marrow of mouse sepsis models

As shown in figure 3, compared with the control and sham groups, the percentage of CD $11 \mathrm{~b}+/ \mathrm{Gr}-1+$ cells in the blood was significantly higher in the CLP group (mean: $33.6 \pm 2.4 \%$ vs $6.9 \pm 1.0 \%$ and $6.8 \pm 0.8 \%$, respectively, $\mathrm{P}<0.001)$. Furthermore, in the CLPS group, the percentage of CD11 $\mathrm{b}+/ \mathrm{Gr}-1+$ cells in the blood was lower than that in the CLP group (mean: $19.3 \pm 1.3 \%$ vs $33.6 \pm 2.4 \%, P<0.001$ ). However, the percentage of CD11b+/Gr-1+ cells in the spleen was significantly lower in the CLP group than in the control and sham groups (mean: $2.5 \pm 0.3 \%$ vs $5.46 \pm 0.3 \%$ and $4.80 \pm 0.3 \%$, respectively, $P<0.001$ ). In bone marrow, the percentage of CD11 b+/Gr-1+ cells in the CLP group was similar to the CLPS, control and sham groups (mean: $28.4 \pm 1.2 \%$ vs $24.0 \pm 0.7 \%, 26.4 \pm 0.5 \%$ and $28.8 \pm 1.3 \%$, respectively, $P>0.05$ ).

\section{Cardiac function of mouse sepsis models}

In the sepsis group, the EF\% and FS\% were significantly lower than in the control and sham groups (EF\%: $56.0 \pm 3.0 \%$ vs $76.1 \pm 3.0 \%$ and $73.0 \pm 3.4 \%$, respectively, $P<0.001 ; F S \%: 27.4 \pm 1.0$ vs $45.4 \pm 1.4 \%$ and $42.0 \pm 1.7 \%$, respectively, $P<0.001)$. In the CLPS group, the $E F \%$ and $F S \%$ were significantly higher than in the CLP group (EF\%: $64.2 \pm 4.6 \%$ vs $56.0 \pm 3.0 \%, P<0.001 ; F S \%: 35.3 \pm 2.2 \%$ vs $27.4 \pm 1.0 \%, P<0.001$, figure 4 ).

\section{The plasma concentration of troponin I (Tnl), NT-proBNP and the expression of inflammatory factors in mouse sepsis models}

The plasma concentration of Tnl was significantly higher in the CLP group than that in the control, sham and CLPS groups $(6.23 \pm 0.24 \mathrm{ng} / \mathrm{mL}$ vs $0.03 \pm 0.01 \mathrm{ng} / \mathrm{mL}, 0.04 \pm 0.01 \mathrm{ng} / \mathrm{mL}$ and $3.68 \pm 0.17 \mathrm{ng} / \mathrm{mL}$, respectively, $\mathrm{P}<0.05)$. The plasma NT-proBNP concentration was significantly higher in the CLP group 
than that in the control, sham and CLPS groups $(2799 \pm 536 \mathrm{pg} / \mathrm{mL}$ vs $93 \pm 8.0 \mathrm{pg} / \mathrm{mL}, 100 \pm 4.0 \mathrm{pg} / \mathrm{mL}$ and $1011 \pm 148 \mathrm{pg} / \mathrm{mL}$, respectively, $P<0.05$, figure 5A, B).

The plasma concentration of IL- 6 was also higher in the CLP group than that in the control, sham and CLPS groups $(19.5 \pm 0.3 \mathrm{pg} / \mathrm{mL}$ vs $9.8 \pm 0.7 \mathrm{pg} / \mathrm{mL}, 4.2 \pm 1.0 \mathrm{pg} / \mathrm{mL}$ and $4.1 \pm 0.3 \mathrm{pg} / \mathrm{mL}$, respectively, $\mathrm{P}<0.05)$. Furthermore, the plasma concentration of IL-1 $\beta$ in the CLP group was higher than that in the control, sham and CLPS groups $(27.5 \pm 1.1 \mathrm{pg} / \mathrm{mL}$ vs $8.6 \pm 0.1 \mathrm{pg} / \mathrm{mL}, 8.3 \pm 0.2 \mathrm{pg} / \mathrm{mL}$ and $15.4 \pm 0.8 \mathrm{pg} / \mathrm{mL}$, respectively, $P<0.05$, figure $5 C, D)$.

RT-PCR showed that the expression of IL- 6 and IL-1 $\beta$ was significantly higher in the CLP group than that in the control and sham groups. In the CLPS group, the expression of IL- 6 and IL- $1 \beta$ was downregulated more than in the CLP group (Figure 6C, D).

\section{Expression of CD11b and Gr-1 in myocardium tissue and cell apoptosis analysis}

HE staining showed the number of inflammatory cells that gathered in the myocardium tissue in the CLP group compared with the control and sham groups. In the CLPS group, the number of inflammatory cells was decreased more than in the CLP group (Figure 7). Masson staining showed that collagen fibres were detected instead of muscle fibres in sepsis (Figure 7). TUNEL staining showed that apoptotic cardiomyocytes had no obvious change between the control and sham groups. In the CLP group, apoptotic cardiomyocytes increased markedly in the myocardium tissue. However, apoptotic cardiomyocytes decreased in the CLPS group compared with the CLP group (Figure 7). Immunofluorescence indicated that $\mathrm{CD} 11 \mathrm{~b}+\mathrm{Gr}-1+$ cells in the myocardium tissue tended to be higher in the CLP group than in the control or sham groups. In the CLPS group, the number of CD11b+Gr-1+ cells was lower than in the CLP group (Figure 8). RT-PCR further showed that the expression of CD11b and Gr-1 was significantly higher in the CLP group than in the control and sham groups. In the CLPS group, the expression of CD11b and Gr-1 was lower than in the CLP group (Figure 6A, B).

\section{mTOR/P53 signalling pathway participated in sepsis-induced myocardial injury}

In the CLP group, mTOR was dephosphorylated and the expression of P53 and caspase-3 was upregulated compared to the control and sham groups. In the CLPS group, the phosphorylation of mTOR was higher than in the CLP group. The expression of P53 and caspase-3 was downregulated in the CLPS group compared to the CLP group (Figure 9).

\section{Discussion}

In this study, we revealed that spleen-derived CD11b+Gr-1+ cells mobilize into circulation and myocardial tissue and further inhibit the phosphorylation of mTOR that leads to apoptosis of cardiac myocytes through the upregulated expression of P53 and caspase-3 in sepsis-induced myocardial injury.

Severe sepsis contributes to the main causes of mortality in ICU patients and increases the medical burden $[14,15]$. The inflammatory response is a key characteristic in the development of organ injury in 
sepsis. Myocardial dysfunction is an important characteristic in sepsis that is associated with poor prognoses such as cognitive impairment and functional disability [16]. Pro-inflammatory factors released by inflammatory cells are a major mechanism participating in the progress of sepsis-induced myocardial dysfunction $[17,18]$. CD11 $+G r-1+$ cells are a group of mononuclear cells usually defined as myeloidderived suppressor cells (MDSCs). In humans, MDSCs are defined as CD14-CD11b+ [8]. CD11b+Gr-1+ cells have numerous functions, including producing pro-inflammatory cytokines and immunoregulatory properties that migrate to injured or infected sites $[19,20]$. CD11b+Gr-1+ cells participate in the systemic inflammatory response through different pathways during early and late sepsis [21]. However, under different circumstances, $C D 11 \mathrm{~b}+\mathrm{Gr}-1+$ cells have a paradoxical role in sepsis, trauma and ischaemic injury $[5,22]$. It has remained in doubt whether $C D 11 b+G r-1+$ cells are protective or injury-promoting cells. A widely accepted viewpoint considered that in different disease phases, different groups of CD11b+Gr$1+$ cells showed contrary effects [6]. In this study, we indicated that CD11b+Gr-1+ cells migrated to the circulation of sepsis patients and the myocardial tissue in animal sepsis models. The concentration of blood pro-inflammatory cytokines increased dramatically in both patients and animal models, which further influenced the signalling pathway associated with cell survival.

Bone marrow is rich in mononuclear cells containing CD11b+Gr-1+ cells. Various research has indicated that bone marrow is the major source of $C D 11 b+G r-1+$ cells [23]. However, the spleen contains numerous monocytes or promonocytes. In myocardial infarction, spleen-derived CD11b+Gr-1+ cells contributed maximally to circulation and myocardial tissue $[10,24]$. In other pathological injuries, splenic reservoir $\mathrm{CD} 11 \mathrm{~b}+\mathrm{Gr}-1+$ cells were also the major source of circulating inflammatory cells [25]. Our research also indicated that in sepsis-induced myocardial injury, spleen-derived CD11b+Gr-1+ cells were the major source that rapidly mobilized into circulation and the target organ to trigger an inflammatory reaction and damage of the organ through the CLPS model. The spleen and its primary cells have the potential to become a probable new therapeutic target.

mTOR is a key molecule that regulates $\mathrm{CD} 11 \mathrm{~b}+\mathrm{Gr}-1+$ differentiation and immunomodulation during an inflammatory reaction $[26,27]$. The relationship between $\mathrm{mTOR}$ and organ damage is a key point that attracts a number of researchers. Previous research suggested that the activation of mTOR protected against murine immunological hepatic injury through limiting the recruitment of CD11b+Gr-1+Ly6Chigh cells [28]. However, in different organs and microenvironments, the role of mTOR showed an obvious heterogeneity. The activation of mTOR associated with vasodilator and pro-inflammatory mediator formation contributes to LPS-induced hypotension and inflammation [29]. In acute kidney injury, $\mathrm{CD} 11 \mathrm{~b}+\mathrm{Gr}-1+$ cells are recruited to the injured kidney following mTOR inhibition, and further protect mouse kidneys against AKI in vivo [27]. The key role of mTOR may act to adjust the balance of proinflammatory and anti-inflammatory responses [26]. Our data indicated that in sepsis-induced myocardial injury, the expression of phosphorylated mTOR in myocardial tissue was lower than that in the control group. Nevertheless, phosphorylated mTOR was highly expressed in CLPS mice, similar to healthy controls, due to few $\mathrm{CD} 11 \mathrm{~b}+\mathrm{Gr}-1+$ cells that mobilized from the spleen and migrated to the myocardial tissue. These results suggest that the inflammatory reaction inhibits the activation of mTOR and further leads to myocardial tissue damage in sepsis. 
The mTOR signalling pathway has been widely studied in the senescence of tumour cells and immortalized cell lines [30]. It had been proven that the mTOR signalling pathway plays a key role in cell apoptosis and senescence. Inhibition of MTOR activates the expression of P53 and further leads to cell senescence and organ dysfunction [31]. P53 is considered a key molecular that regulates the cell cycle and loss of cell function. A previous study suggested that P53 mediates the accelerated onset of senescence of endothelial progenitor cells in diabetes [32]. Nevertheless, activation of the p53 tumour suppressor can lead to cell cycle arrest [33]. However, the relationship between the mTOR pathway and cell and organ injury is still under debate. In LPS-induced rat damage models, activation of mTOR is the key mechanism involved in inflammation [29]. In sepsis, activation of the mTOR signalling pathway contributes to long-term neuronal loss [34]. Our research demonstrated that in sepsis-induced myocardial injury, expression of phosphorylated mTOR was significantly inhibited and further led to the upregulation of P53, and finally, to cell apoptosis, which resulted in impaired heart function. These data may partly explain the role of mTOR/P53 in sepsis-induced myocardial injury.

There are several apparent limitations in this study. Whether the mTOR signalling pathway is involved in the differentiation of $C D 11 b+G r-1+$ cells and the roles of different types of MDSCs need to be further studied.

\section{Conclusion}

In a mouse sepsis-induced myocardial injury model, splenic reservoir CD11b+Gr-1+ cells rapidly migrated into circulation and the target organ, further impairing heart function via the high expression of P53 through the inhibition of mTOR

\section{Abbreviations}

\section{Abbreviations}

CLP: caecum ligation and puncture; CLPS: CLP+splenectomy; mTOR: mammalian target of rapamycin; HE staining: hematoxylin-eosin staining; IL: interleukin; TUNEL: transferase-mediated deoxyuridine triphosphate-biotin nick end labeling; DAPI: 4',6-diamidino-2-phenylindole. $\mathrm{N}$ terminal pro B type natriuretic peptide: NT-proBNP.

\section{Declarations}

\section{Ethics approval and consent to participate}

This study was approved by the Yi Ji Shan Hospital Animal Care Committee and Yi Ji Shan Hospital Ethics Committee. Written informed consent to use the animals was obtained from Yi Ji Shan Hospital Animal Care Committee. The study has informed consent from all patients and healthy control. The mice were handled according to the guidelines of the Local Ethics Committee for Animal Experimentation. 


\section{Consent for publication}

Not applicable

\section{Availability of data and materials}

The datasets used and /or analyzed in the current study are available from the corresponding author on reasonable request.

\section{Competing interest}

The authors declare that they have no competing interest.

\section{Funding}

This work was supported by National Natural Science Foundation of China (81700265 to Cong Fu and 81702092 to Yuhan Cao) and Colleges and Universities Natural \& Science Fund of Anhui (No. KJ2017A270 to Cong Fu, No. KJ2017A269 to Yuhan Cao).

The funders had no role in any stage of the design and conduct of the study, collection, management, analysis, and interpretation of data in the study, or the preparation, review, or approval of the manuscript.

\section{Authors' contributions}

CF: conception/design/drafting. QCX: conception/design/drafting. SXT: design/statistics. YHC: design/statistics. CL: design/revising. JL: design/revising. YHW: design/revising. YQ: design/revising. FS: design/revising. JMG: design/revising. QF: design/revising. YL: design/revising. All the authors have read and approved the manuscript.

\section{Acknowledgements}

We thank Dr. Yueping Chen, Dr. Yongli Zhao, Dr. Xiang Kong, Dr. Qing Zhai and Dr. Jinhan Chen in Department of Endocrine, Yi Ji Shan hospital for their kindly support.

\section{References:}

1. Hotchkiss RS, Karl IE: The pathophysiology and treatment of sepsis. N Engl J Med 2003, 348(2):138150.

2. Oberholzer A, Oberholzer C, Moldawer LL: Sepsis syndromes: understanding the role of innate and acquired immunity. SHOCK 2001, 16(2):83-96.

3. Shubin NJ, Monaghan SF, Ayala A: Anti-inflammatory mechanisms of sepsis. Contrib Microbiol 2011, 17:108-124.

4. Ueha S, Shand FH, Matsushima K: Myeloid cell population dynamics in healthy and tumor-bearing mice. INT IMMUNOPHARMACOL 2011, 11(7):783-788. 
5. Cuenca AG, Delano MJ, Kelly-Scumpia KM, Moreno C, Scumpia PO, Laface DM, Heyworth PG, Efron PA, Moldawer LL: A paradoxical role for myeloid-derived suppressor cells in sepsis and trauma. MOL MED 2011, 17(3-4):281-292.

6. Brudecki L, Ferguson DA, McCall CE, El GM: Myeloid-derived suppressor cells evolve during sepsis and can enhance or attenuate the systemic inflammatory response. INFECT IMMUN2012, 80(6):2026-2034.

7. Peranzoni E, Zilio S, Marigo I, Dolcetti L, Zanovello P, Mandruzzato S, Bronte V: Myeloid-derived suppressor cell heterogeneity and subset definition. CURR OPIN IMMUNOL 2010, 22(2):238-244.

8. Gabrilovich DI, Nagaraj S: Myeloid-derived suppressor cells as regulators of the immune system. NAT REV IMMUNOL 2009, 9(3):162-174.

9. Dunay IR, Damatta RA, Fux B, Presti R, Greco S, Colonna M, Sibley LD: Gr1(+) inflammatory monocytes are required for mucosal resistance to the pathogen Toxoplasma gondii. IMMUNITY 2008, 29(2):306-317. 10. Swirski FK, Nahrendorf M, Etzrodt M, Wildgruber M, Cortez-Retamozo V, Panizzi P, Figueiredo JL, Kohler RH, Chudnovskiy A, Waterman $\mathrm{P}$ et al: Identification of splenic reservoir monocytes and their deployment to inflammatory sites. SCIENCE 2009, 325(5940):612-616.

11. Wichterman KA, Baue AE, Chaudry IH: Sepsis and septic shock-a review of laboratory models and a proposal. J SURG RES 1980, 29(2):189-201.

12. Spiller F, Costa C, Souto FO, Vinchi F, Mestriner FL, Laure HJ, Alves-Filho JC, Freitas A, Rosa JC, Ferreira SH et al: Inhibition of neutrophil migration by hemopexin leads to increased mortality due to sepsis in mice. Am J Respir Crit Care Med 2011, 183(7):922-931.

13. Sheng Z, Yao Y, Li Y, Yan F, Huang J, Ma G: Bradykinin preconditioning improves therapeutic potential of human endothelial progenitor cells in infarcted myocardium. PLOS ONE 2013, 8(12):e81505.

14. Dombrovskiy VY, Martin AA, Sunderram J, Paz HL: Rapid increase in hospitalization and mortality rates for severe sepsis in the United States: a trend analysis from 1993 to 2003. CRIT CARE MED 2007, 35(5):1244-1250.

15. Lagu T, Rothberg MB, Shieh MS, Pekow PS, Steingrub JS, Lindenauer PK: Hospitalizations, costs, and outcomes of severe sepsis in the United States 2003 to 2007. CRIT CARE MED 2012, 40(3):754-761. 16. Gaieski DF, Edwards JM, Kallan MJ, Carr BG: Benchmarking the incidence and mortality of severe sepsis in the United States. CRIT CARE MED 2013, 41(5):1167-1174.

17. Gamkrelidze M, Intskirveli N, Vardosanidze K, Goliadze L, Chikhladze K, Ratiani L: Myocardial dysfunction during septic shock (review). Georgian Med News 2014(237):40-46.

18. Fan TT, Feng XY, Yang YZ, Gao F, Liu Q: Downregulation of PI3K-gamma in a mouse model of sepsisinduced myocardial dysfunction. CYTOKINE 2017, 96:208-216.

19. Xia S, Sha H, Yang L, Ji Y, Ostrand-Rosenberg S, Qi L: Gr-1+ CD11b+ myeloid-derived suppressor cells suppress inflammation and promote insulin sensitivity in obesity. J BIOL CHEM 2011, 286(26):23591- 
23599.

20. Ochoa AC, Zea AH, Hernandez C, Rodriguez PC: Arginase, prostaglandins, and myeloid-derived suppressor cells in renal cell carcinoma. CLIN CANCER RES 2007, 13(2 Pt 2):721s-726s.

21. Brudecki L, Ferguson DA, McCall CE, El GM: Myeloid-derived suppressor cells evolve during sepsis and can enhance or attenuate the systemic inflammatory response. INFECT IMMUN2012, 80(6):2026-2034.

22. Huang J, Lv G, Min Y, Yang L, Lin PC: Intravenous administration of Gr-1+CD11b+ myeloid cells increases neovascularization and improves cardiac function after heart infarction. INT J CARDIOL 2013, 168(2):1702-1705.

23. Wei WC, Lin SY, Lan CW, Huang YC, Lin CY, Hsiao PW, Chen YR, Yang WC, Yang NS: Inhibiting MDSC differentiation from bone marrow with phytochemical polyacetylenes drastically impairs tumor metastasis. Sci Rep 2016, 6:36663.

24. Zhang Y, Li H, Zhao G, Sun A, Zong NC, Li Z, Zhu H, Zou Y, Yang X, Ge J: Hydrogen sulfide attenuates the recruitment of $\mathrm{CD} 11 \mathrm{~b}(+) \mathrm{Gr}-1(+)$ myeloid cells and regulates $\mathrm{Bax} / \mathrm{Bcl}-2$ signaling in myocardial ischemia injury. Sci Rep 2014, 4:4774.

25. Yao T, Lu W, Zhu J, Jin X, Ma G, Wang Y, Meng S, Zhang Y, Li Y, Shen C: Role of CD11b+Gr-1+ myeloid cells in AGEs-induced myocardial injury in a mice model of acute myocardial infarction. Int $J$ Clin Exp Pathol 2015, 8(3):3238-3249.

26. Cobbold SP: The mTOR pathway and integrating immune regulation. IMMUNOLOGY 2013, 140(4):391-398.

27. Zhang C, Wang S, Li J, Zhang W, Zheng L, Yang C, Zhu T, Rong R: The mTOR signal regulates myeloidderived suppressor cells differentiation and immunosuppressive function in acute kidney injury. $C E L L$ DEATH DIS 2017, 8(3):e2695.

28. Zhang Y, Bi Y, Yang H, Chen X, Liu H, Lu Y, Zhang Z, Liao J, Yang S, Chu Y et al: mTOR limits the recruitment of $\mathrm{CD} 11 \mathrm{~b}+\mathrm{Gr} 1+\mathrm{Ly} 6 \mathrm{Chigh}$ myeloid-derived suppressor cells in protecting against murine immunological hepatic injury. J Leukoc Biol 2014, 95(6):961-970.

29. Temiz-Resitoglu M, Kucukkavruk SP, Guden DS, Cecen P, Sari AN, Tunctan B, Gorur A, Tamer-Gumus L, Buharalioglu CK, Malik KU et al: Activation of mTOR/lkappaB-alpha/NF-kappaB pathway contributes to LPS-induced hypotension and inflammation in rats. EUR J PHARMACOL 2017, 802:7-19.

30. Dando I, Cordani M, Donadelli M: Mutant p53 and mTOR/PKM2 regulation in cancer cells. IUBMB LIFE 2016, 68(9):722-726.

31. Sung JY, Lee KY, Kim JR, Choi HC: Interaction between mTOR pathway inhibition and autophagy induction attenuates adriamycin-induced vascular smooth muscle cell senescence through decreased expressions of p53/p21/p16. EXP GERONTOL 2018, 109:51-58. 
32. Rosso A, Balsamo A, Gambino R, Dentelli P, Falcioni R, Cassader M, Pegoraro L, Pagano G, Brizzi MF: p53 Mediates the accelerated onset of senescence of endothelial progenitor cells in diabetes. $\mathrm{J} B / O L$ CHEM 2006, 281(7):4339-4347.

33. Engeland $\mathrm{K}$ : Cell cycle arrest through indirect transcriptional repression by $\mathrm{p} 53$ : I have a DREAM. $C E L L$ DEATH DIFFER 2018, 25(1):114-132.

34. Guo JN, Tian LY, Liu WY, Mu J, Zhou D: Activation of the Akt/mTOR signaling pathway: A potential response to long-term neuronal loss in the hippocampus after sepsis. NEURAL REGEN RES 2017, 12(11):1832-1842.

\section{Figures}

Figure 1 A

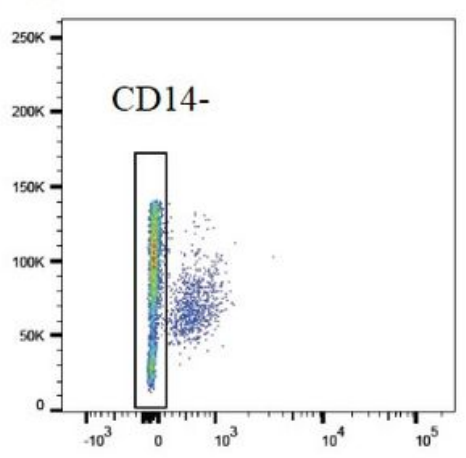

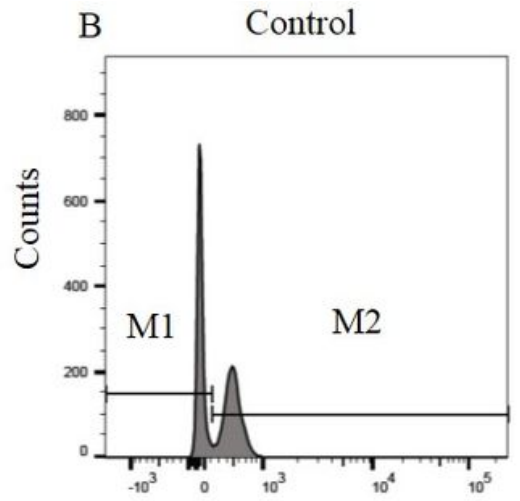

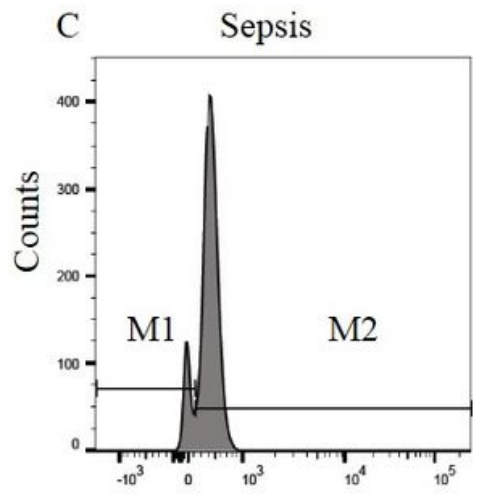

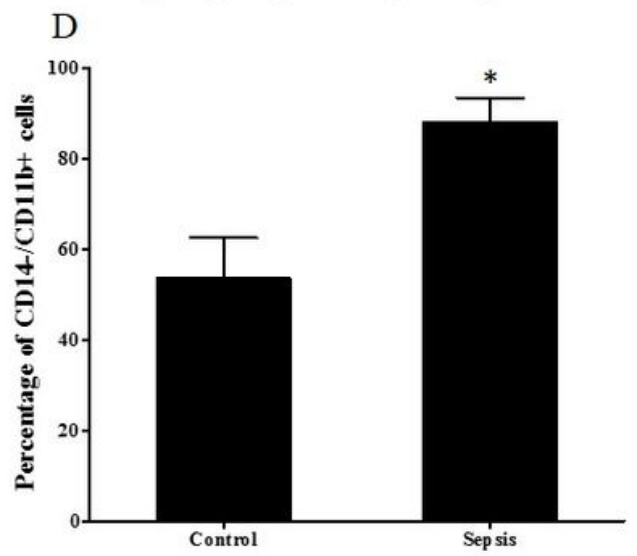

Figure 1

The percentage of CD14-CD11b+ cells in peripheral blood of sepsis patients with myocardial injury. The percentage of $\mathrm{CD} 11 \mathrm{~b}+\mathrm{Gr}-1+$ cells in blood, spleen and bone marrow. A: The gating of CD14 negative cells. $B$ : Representative flow cytometry analyses of CD14-CD11b+ cells expression in control $(n=6)$. C: Representative flow cytometry analyses of CD14-CD11b+ cells expression in sepsis with myocardial injury $(n=10)$. D: Histogram showed the percentage of CD14-CD11b+cells in sepsis was higher than control $(* \mathrm{P}<0.05$ vs control). 
Figure 2
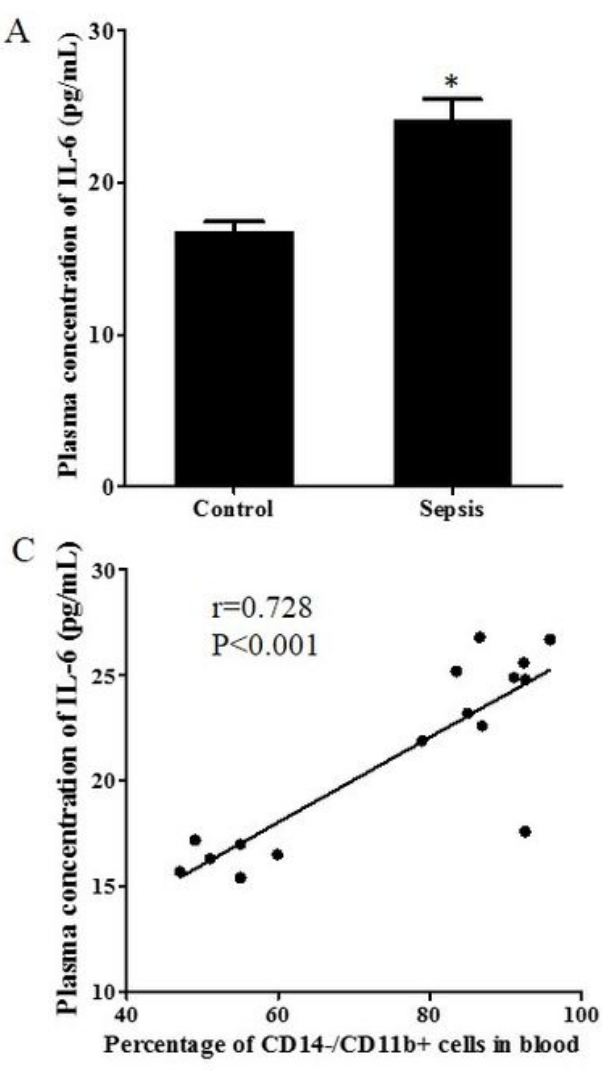

$\mathrm{B}$

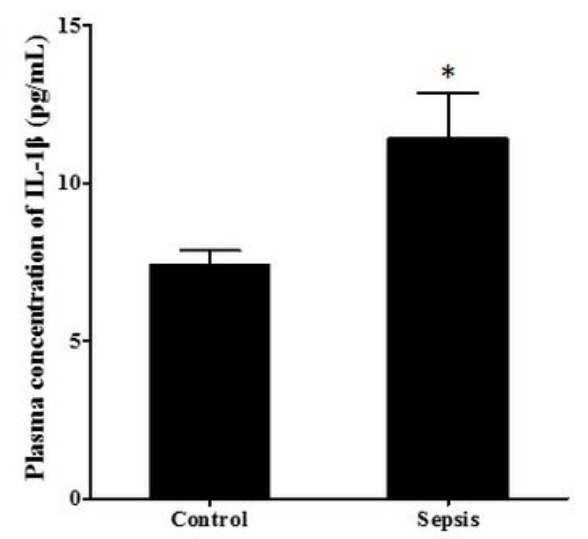

$\mathrm{D}$

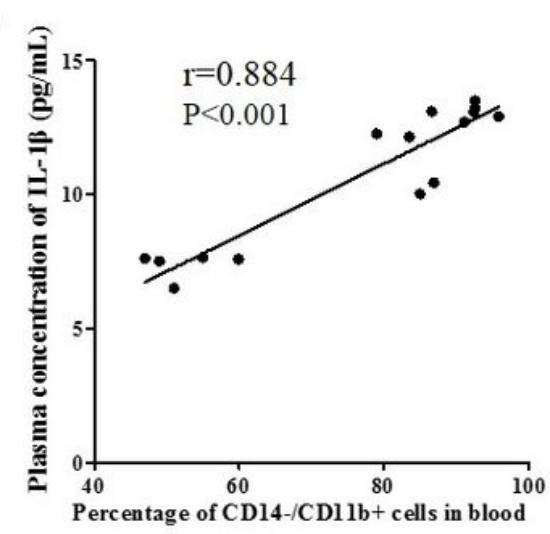

Figure 2

Plasma concentration of IL- 6 and IL-1 $\beta$ in control $(n=6)$ and sepsis with myocardial injury group $(n=10) . A$ : Histogram showed the plasma concentration of IL- 6 was higher in sepsis than control. B: Histogram showed the plasma concentration of IL-1 $\beta$ was higher in sepsis than control. C: The relationship between plasma IL-6 concentration and percentage of CD14-CD11b+ cells. Pearson correlation analysis showed that percentage of circulating CD14-CD11b+ cells has correlated with plasma concentration of IL-6 $(r=0.728, P<0.001)$. D: The relationship between plasma IL-1 $\beta$ concentration and percentage of CD14$\mathrm{CD} 11 \mathrm{~b}+$ cells. Pearson correlation analysis showed that percentage of circulating CD14-CD11b+ cells has correlated with plasma concentration of IL-1 $\beta(r=0.884, P<0.001)$ ( ${ }^{*}<<0.05$ vs control). 
Figure 3

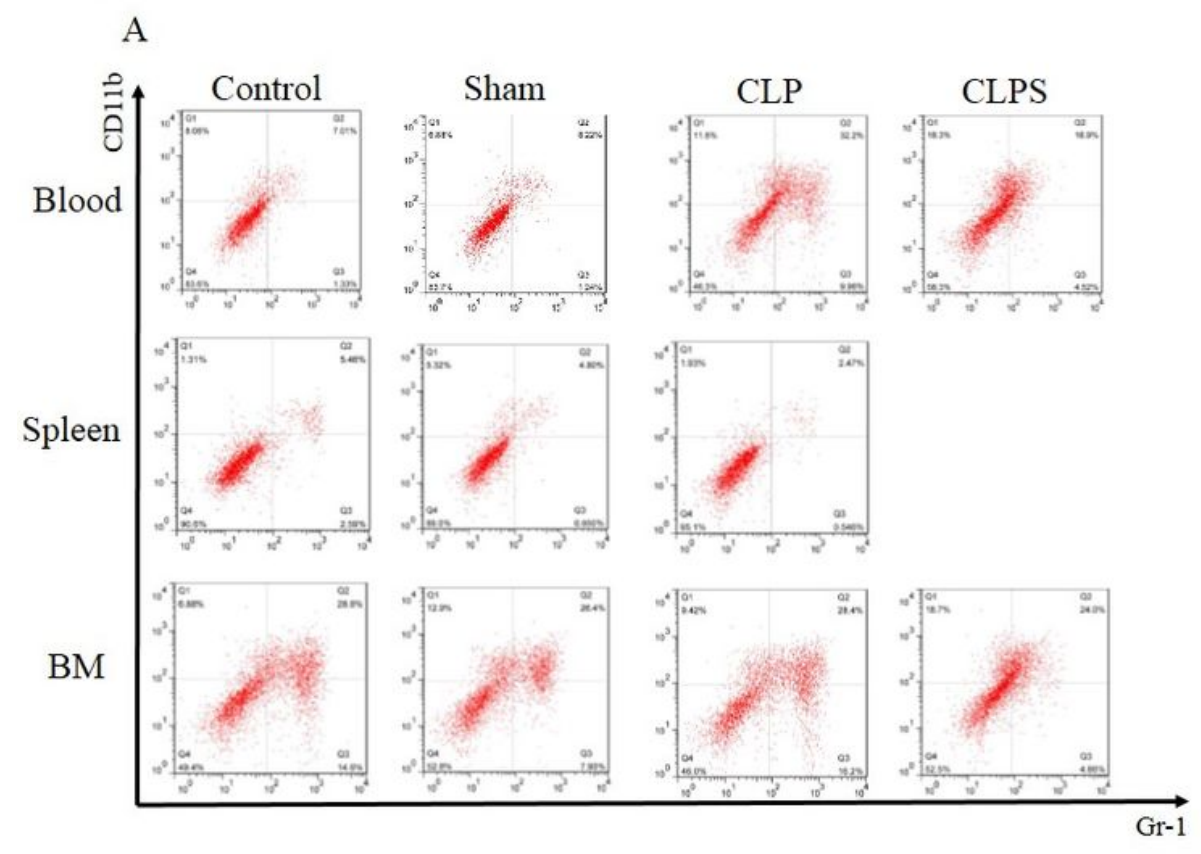

$\mathrm{B}$

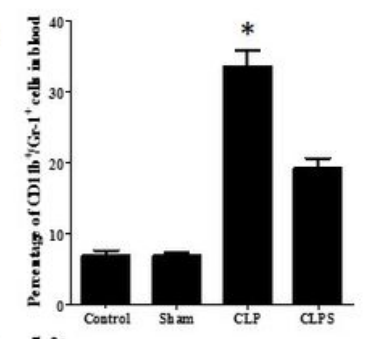

$\mathrm{C}$

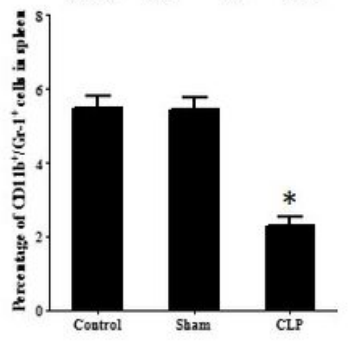

$\mathrm{B}$

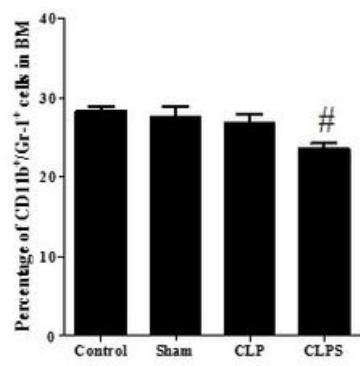

\section{Figure 3}

Flow cytometry analyses of $\mathrm{CD} 11 \mathrm{~b}+\mathrm{Gr}-1+$ cells expression in blood, spleen and bone marrow among four groups. Percentage of circulating CD11b+Gr-1+ cells in sepsis was higher than control, sham and CLPS. However, percentage of splenic CD11b+Gr-1+ cells in sepsis was lower than control and sham. In bone marrow, percentage of $\mathrm{CD} 11 \mathrm{~b}+\mathrm{Gr}-1+$ cells in four groups was similar. A: Representative scatter plot showed the $\mathrm{CD} 11 \mathrm{~b}+\mathrm{Gr}-1+$ cells expression in blood, spleen and bone marrow. B: Histogram showed the percentage of $C D 11 b+G r-1+$ in blood. C: Histogram showed the percentage of CD11b+Gr-1+ in spleen. D: Histogram showed the percentage of $C D 11 b+G r-1+$ in bone marrow $(n=5$ for control and sham, $n=10$ for CLP and CLPS, ${ }^{*}<<0.001$ vs control, sham and CLPS, \#P>0.05 vs control, sham and CLP). 
Figure 4

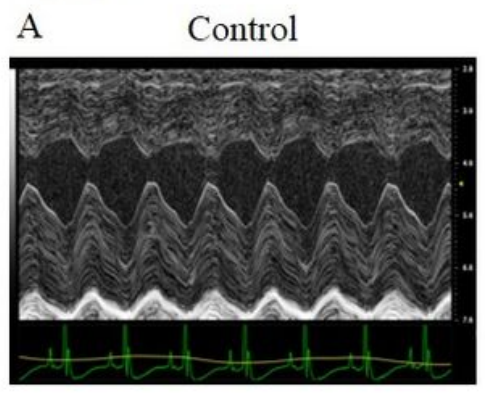

CLP

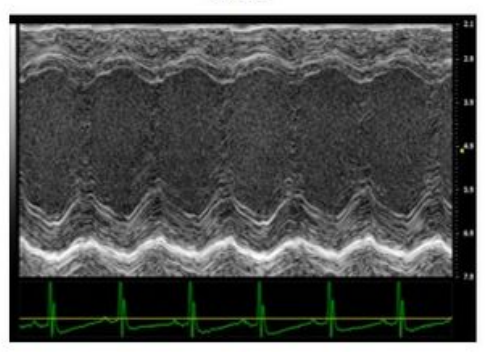

Shame

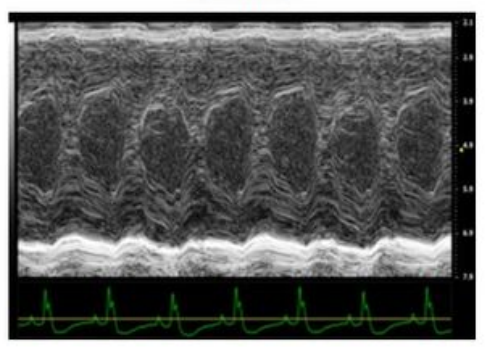

CLPS

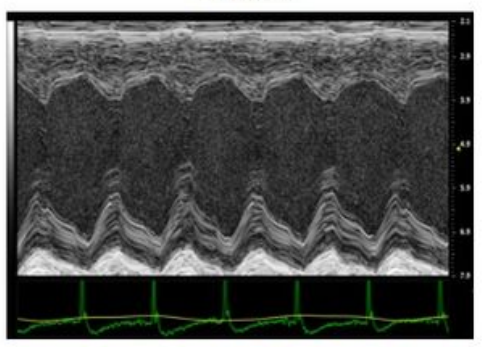

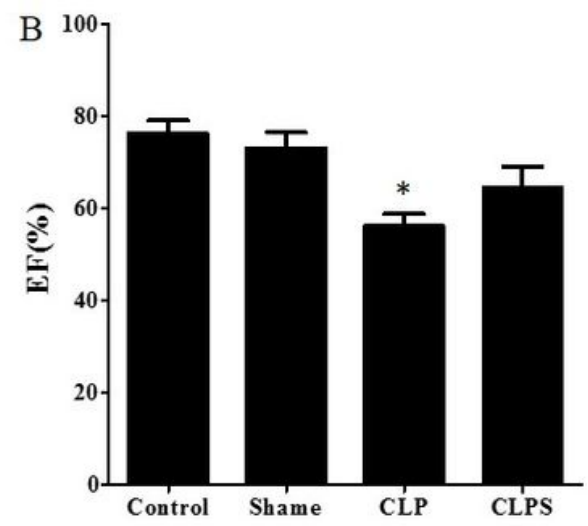

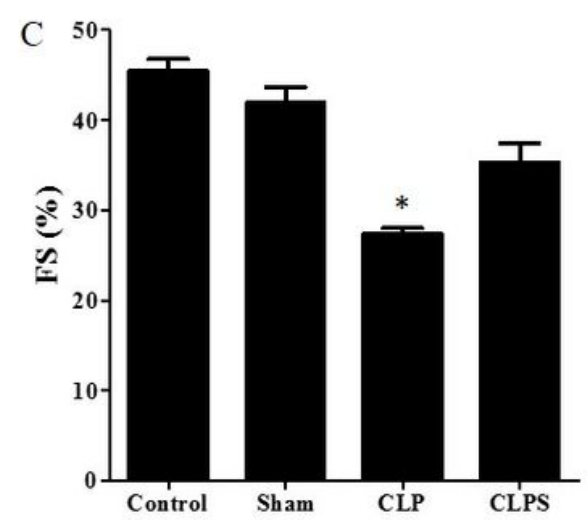

\section{Figure 4}

The cardiac function in four groups. A: The representative echocardiography image of four groups. B: Histogram showed the EF\% among four groups. EF\% in sepsis group was lower than control, sham and CLPS. C: Histogram showed the FS\% among four groups. FS\% in sepsis group was lower than control, sham and CLPS ( $n=5$ for control and sham, $n=10$ for CLP and CLPS, ${ }^{*}<0.001$ vs control, sham and CLPS). 

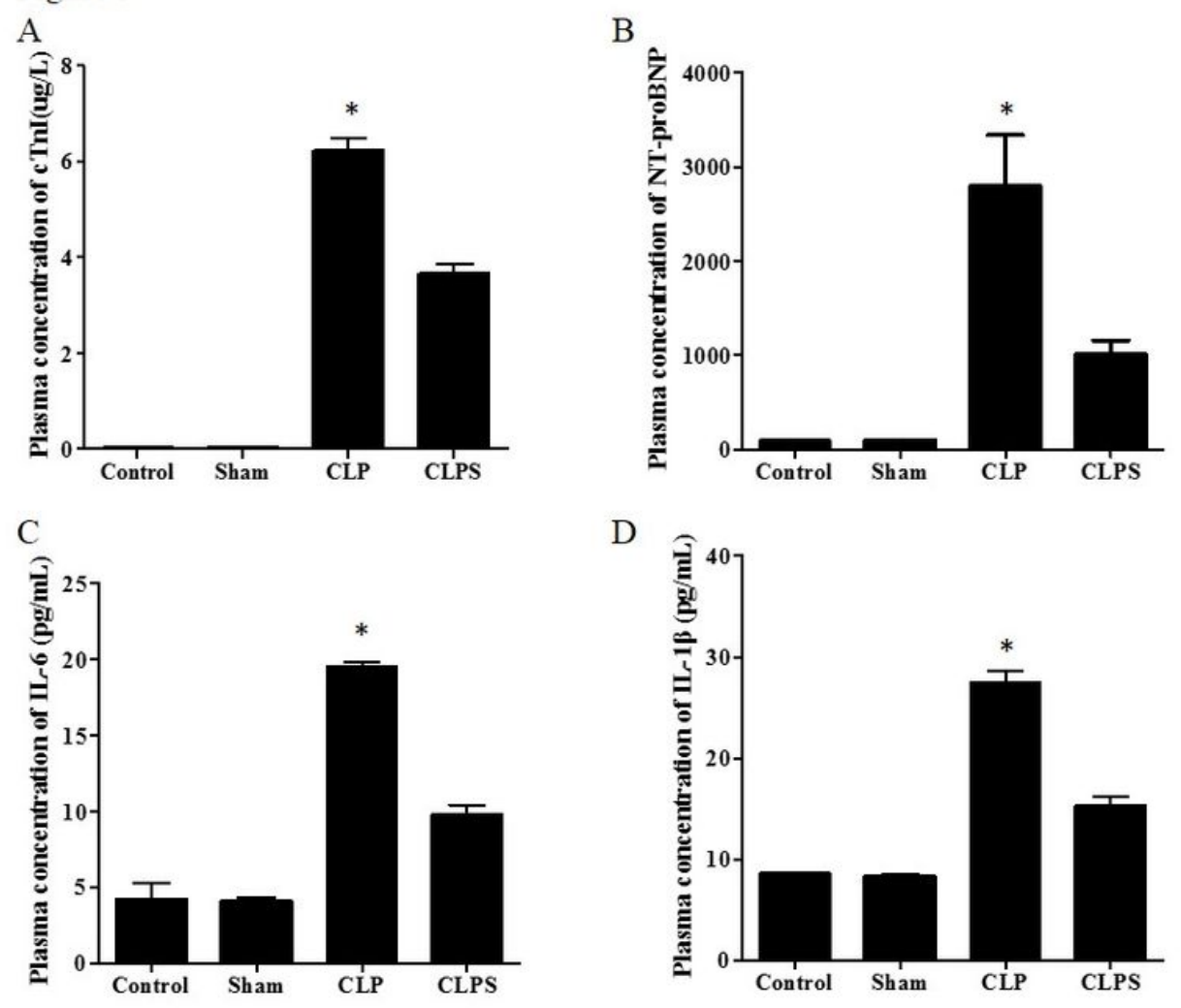

\section{Figure 5}

Plasma concentration of TnI, NT-proBNP, IL- 6 and IL-1 $\beta$ in animal models. A: Histogram showed the plasma concentration of $\mathrm{Tnl}$ in four groups. Plasma concentration of $\mathrm{Tnl}$ in sepsis was higher than other three groups. B: Histogram showed the plasma concentration of NT-proBNP in four groups. Plasma concentration of NT-proBNP in sepsis was higher than other three groups. C: Histogram showed the plasma concentration of IL-6 in four groups. Plasma concentration of IL- 6 was higher than other three groups. D: Histogram showed the plasma concentration of IL-1 $\beta$ in four groups. Plasma concentration of IL-1 $\beta$ was higher than other three groups. ( $n=5$ for control and sham, $n=10$ for CLP and CLPS, ${ }^{*}<0.05$ vs control, sham and CLPS). 
Figure 6
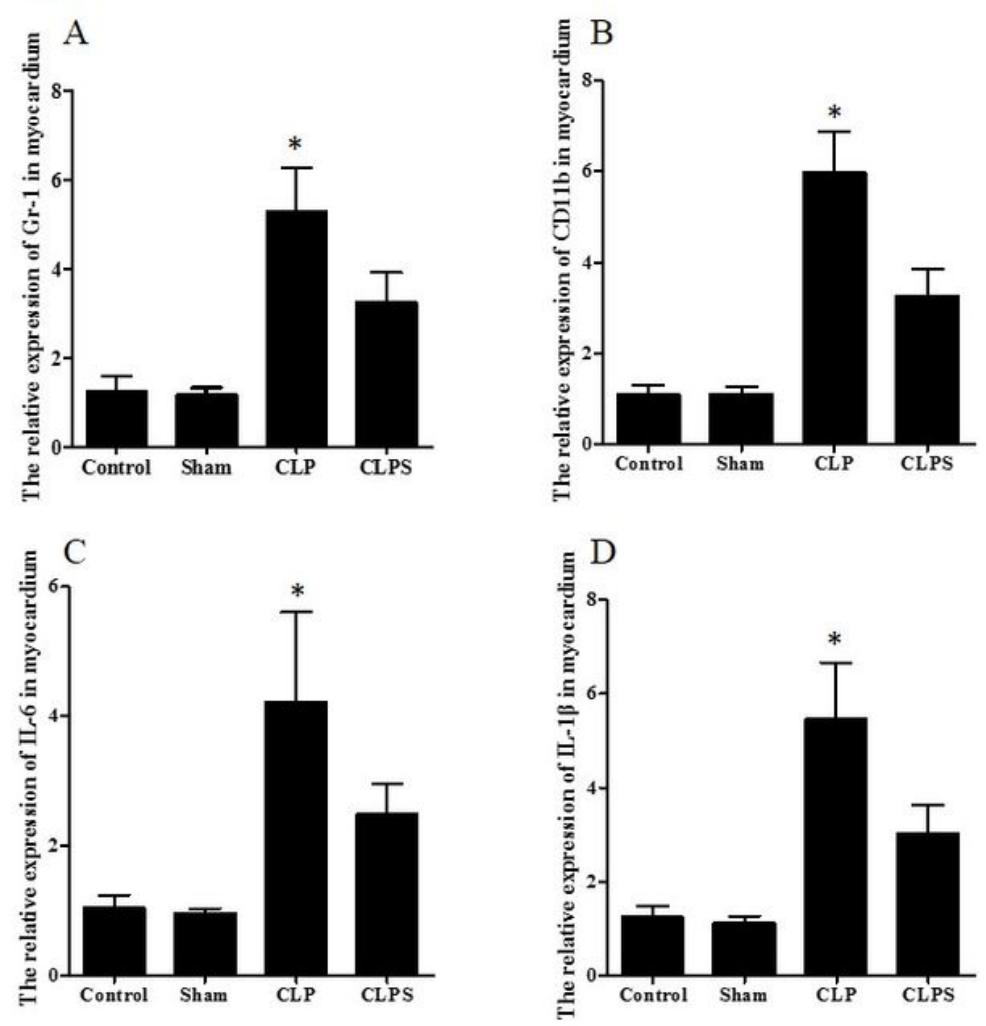

\section{Figure 6}

The relative expression of Gr-1, CD11b, IL-6 and IL-1 $\beta$ in myocardial tissue. A: Histogram showed the relative expression of Gr-1 in four groups. Relative expression of $\mathrm{Gr}-1$ in myocardial tissue was higher than other three groups. B: Histogram showed the Relative expression of $\mathrm{CD} 11 \mathrm{~b}$ in four groups. Relative expression of $\mathrm{CD} 11 \mathrm{~b}$ in myocardial tissue was higher than other three groups. C: Histogram showed the relative expression of IL-6 in four groups. Relative expression of IL-6 in myocardial tissue was higher than other three groups. D: Histogram showed the relative expression of IL-1 $\beta$ in four groups. Relative expression of IL-1 $\beta$ in myocardial tissue was higher than other three groups. ( $n=5$ for control and sham, $\mathrm{n}=10$ for CLP and CLPS, *P<0.05 vs control, sham and CLPS). 


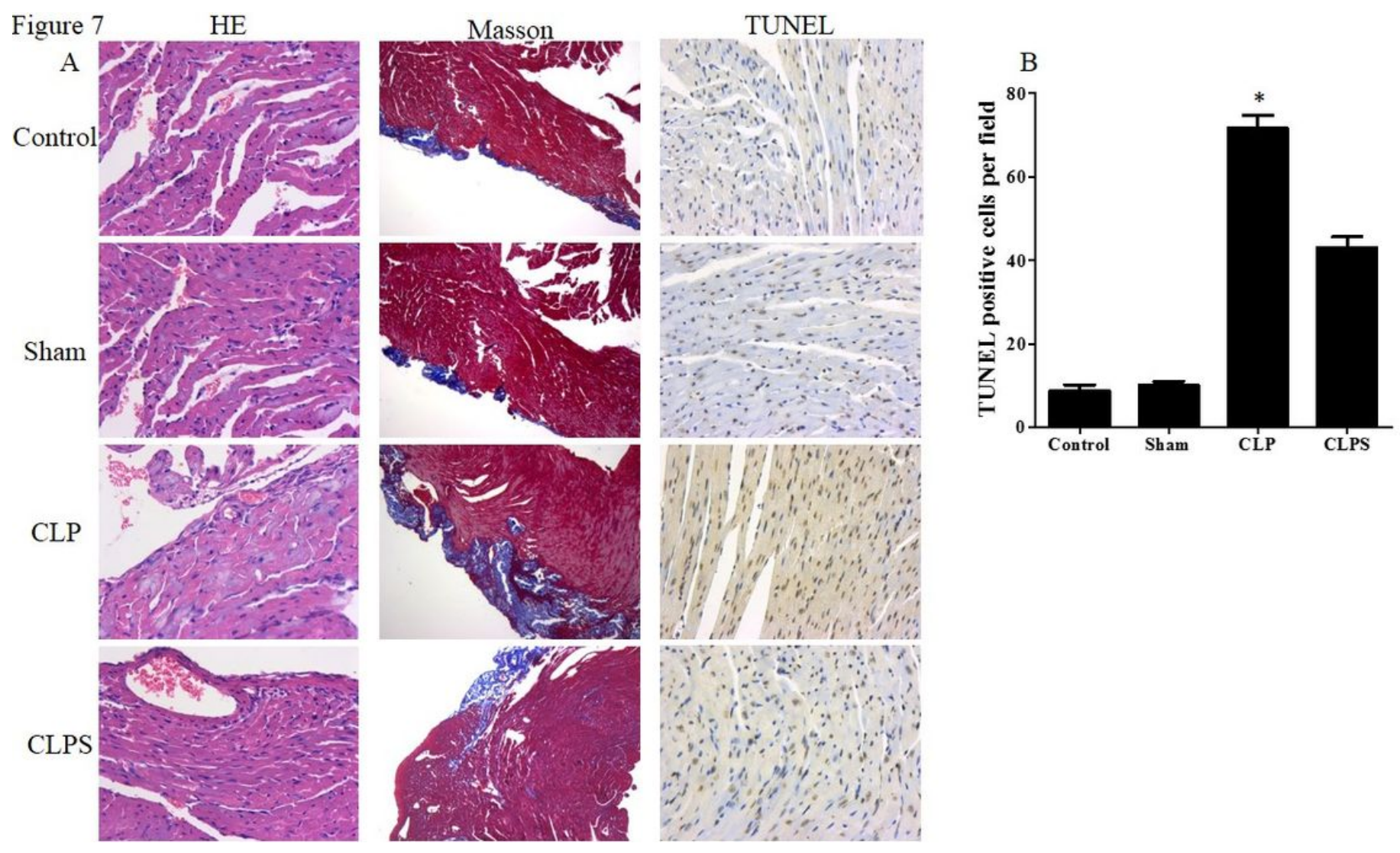

\section{Figure 7}

Monocyte mobilized to myocardial tissue in sepsis and led to myocardial damage. A. The first column: representative HE staining showed that monocyte accumulated to myocardial tissue in CLP group. No obviously inflammatory cells occurred in control, sham and CLPS. Myocardial dissolving and inflammatory cell infiltration was observed in sepsis group (400*). The second column: representative Masson staining photograph. Collagen fiber was detected in sepsis instead of muscle fibers (100*). The third column: representative TUNEL staining showed that apoptotic cardiomyocytes were no obviously changed between control and sham (400*). Markedly increased apoptotic cardiomyocytes in the CLP group. In CLPS, the number of apoptotic cardiomyocytes is lower than CLP. B: Histogram showed the number of apoptotic cardiomyocytes among the four groups. ( $n=5$ for control and sham, $n=10$ for CLP and CLPS, ${ }^{*}<0.05$ vs control, sham and CLPS). 
Figure 8

Gr-1
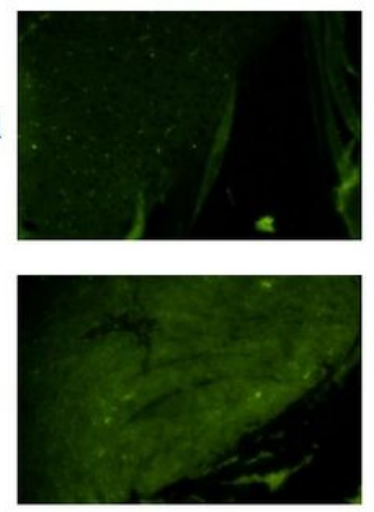

Sham

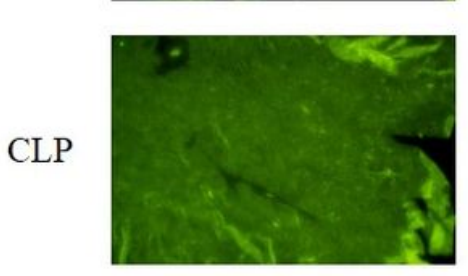

CLPS

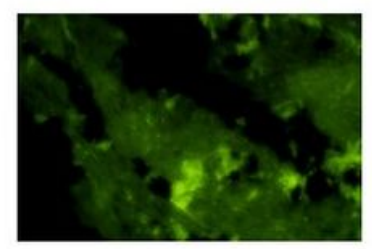

$\mathrm{CD} 11 \mathrm{~b}$
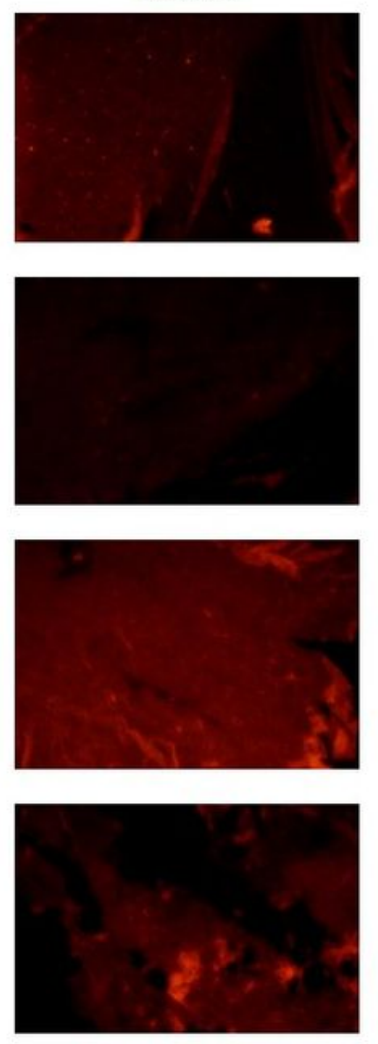

DAPI
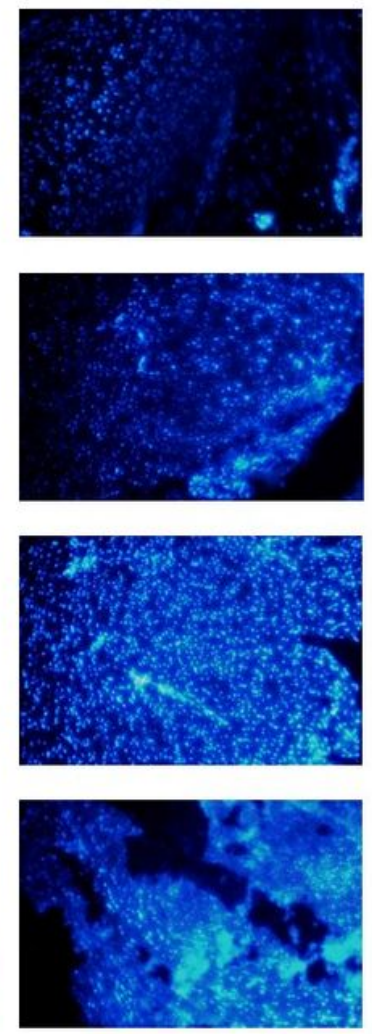

Merge
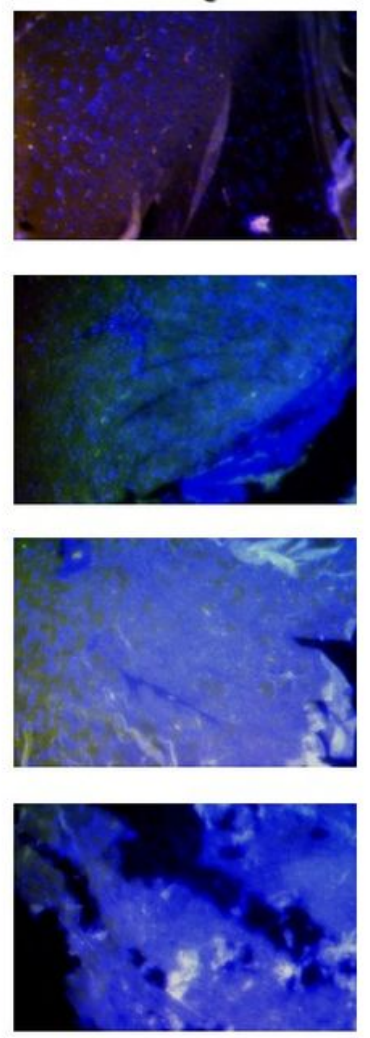

\section{Figure 8}

$\mathrm{CD} 11 \mathrm{~b}+\mathrm{Gr}-1+$ cells mobilized to myocardial tissue in sepsis. Representative immunofluorescence staining showed that in CLP group, both CD11b and Gr-1 expressed in myocardial tissue. In control and sham, CD11b and Gr-1 negatively expressed in myocardial tissue. In CLPS, the expression of CD11b and Gr-1 was lower than CLP ( $n=5$ for control and sham, $n=10$ for CLP and CLPS). 
Figure 9

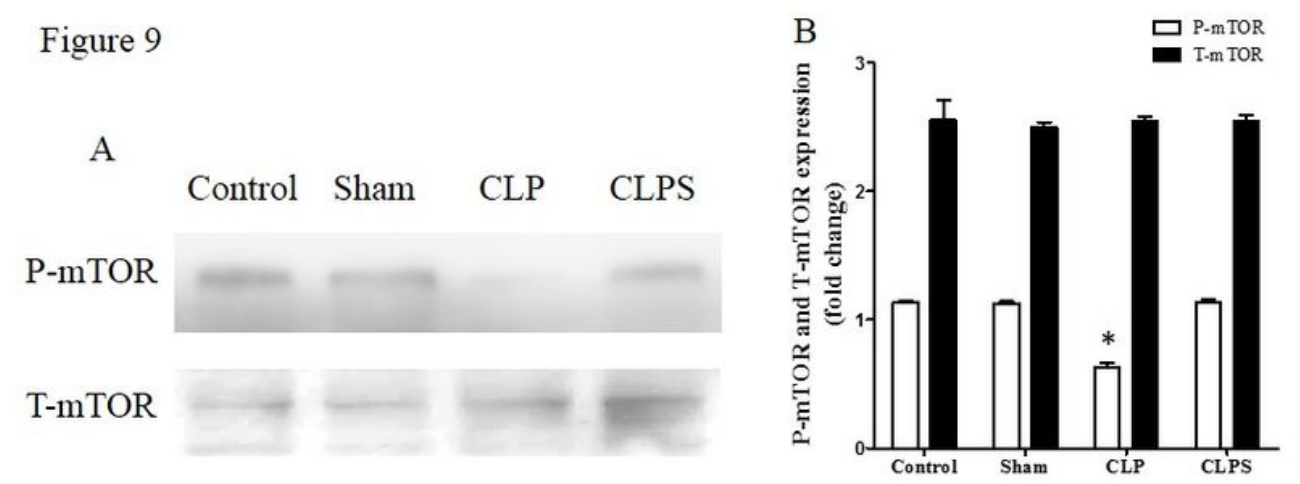

P53

$\mathrm{C}$

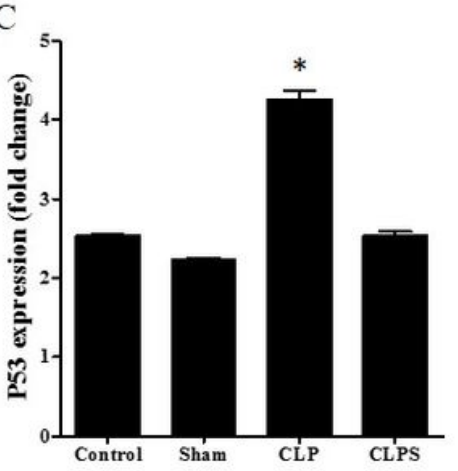

$\mathrm{D}$

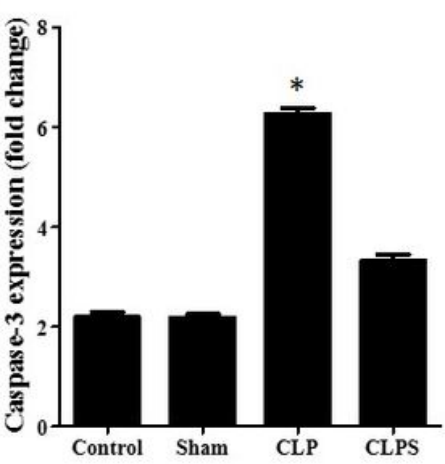

Figure 9

The mTOR/P53 pathway in septic myocardial tissue. A: Representative Western blots normalized to GAPDH showed that in CLP group, the phosphorylation of mTOR was inhibited compared to control and sham. However, the phosphorylation of mTOR was higher in CLPS than CLP. Further, the expression of P53 and caspase-3 was down-regulated in CLPS compared to CLP. B: Densitometry quantitation of protein expression levels are shown as fold changes in histogram ( $n=5$ for control and sham, $n=10$ for CLP and CLPS, * $P<0.05$ vs control, sham and CLPS). 